\title{
Selection Method of Modulation Index and Frequency ratio for Getting the SPWM Minimum Harmonic of Single Phase Inverter
}

\author{
Ant. Ardath Kristi, Bambang Susanto, Agus Risdiyanto, Agus Junaedi, \\ Anwar Muqorobin, Noviadi A. Rachman, Harjono P. Santosa \\ Research Center for Electrical and Mechatronics, Indonesian Institute of Sciences \\ Jl. Cisitu, No. 21/154D, Bandung 40135, Indonesia \\ E-Mail: *ardathmeca@gmail.com,b3nks73@gmail.com, riesdian@gmail.com, \\ sayannga1@gmail.com, anwa006@lipi.go.id, n.ariefrachman@gmail.com, \\ maspridjos@gmail.com
}

Received December 30, 2020; Revised February 2, 2021; Accepted March 8, 2021

\begin{abstract}
Harmonic content is an important parameter in relation to the power generated by inverter. In power conversion technology of inverter, sinusoidal pulse width modulation (SPWM) is the most popular used by many researchers. The advantages of SPWM inverter operation as a conversion technique compared to other inverter types can be seen from the low harmonic distortion in the output voltage of inverter. Therefore, the SPWM signal generation process becomes a determining factor for the performance of the overall system. This paper present the method for selecting the modulation index $\left(m_{a}\right)$ and frequency ratio $\left(m_{f}\right)$ using Cubic Spline Interpolation to get minimum harmonic of SPWM inverter that generated. Both parameters controlled with varied values digitally using microcontroller to generate SPWM, then the output of inverter with and without LC filter was investigated. The results show that the use of Cubic Spline Interpolation method in the selection of $m_{a}$ and $m_{f}$ precisely managed to produce SPWM inverter with minimum harmonic content. At the inverter output, the use of LC filter is not only useful for converting SPWM signals to sinusoidal waveforms but can also reduce harmonic content significantly less than $3 \%$.
\end{abstract}

Keywords: SPWM inverter, harmonic content, modulation index, frequency ratio, Cubic Spline.

\section{INTRODUCTION}

Inverter is one of the few kinds of converters known as DC to AC converter, in other words, this device serves to generate voltage AC singlephase or multi-phase from a DC source [1]. Inverter has widely used in domestic and industrial applications such as AC motor controllers, induction heating, power supply and UPS. The use of inverter also has increased along with the need for renewable energy demand, especially which produced the 
main source of DC stored in batteries or directly consumed by the load. Some renewable energy sources that generate DC supply such as solar cell, fuel cell, thermoelectric, wind energy, and other DC sources.

There are three types of inverter based on output waveform; square wave, modified wave and pure sine wave. The output waveform of the three types of inverter shown in Figure 1.

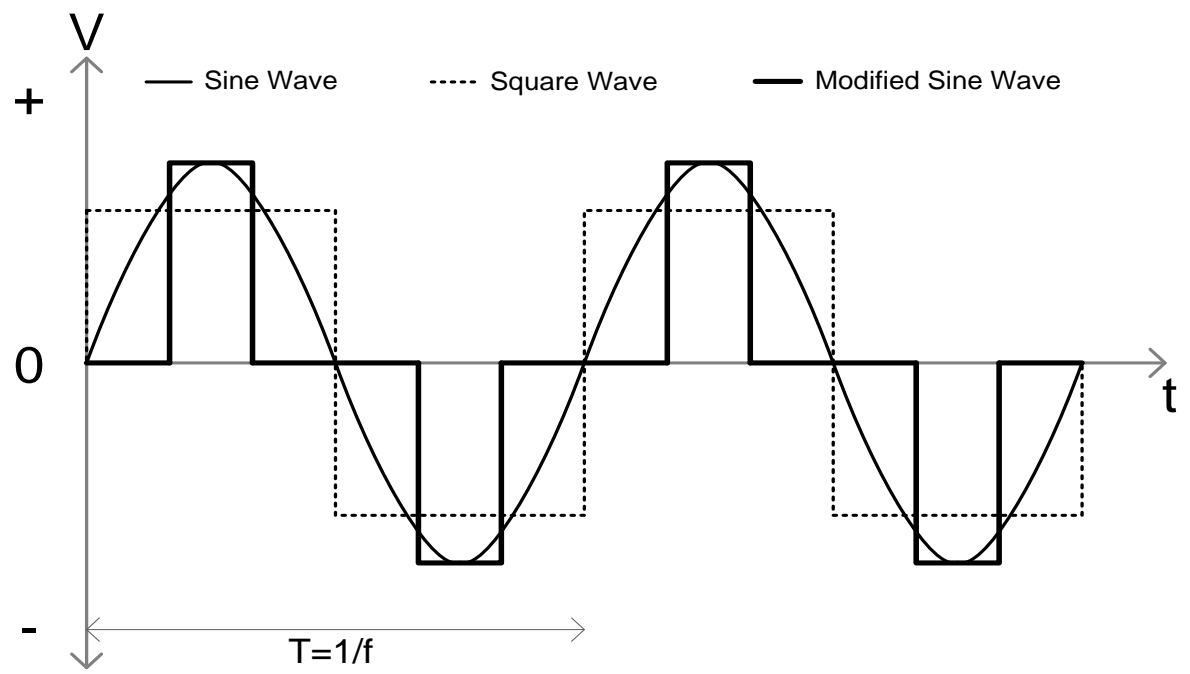

Figure 1. Square Wave, Modified Wave, and Pure Sine Wave

Inverter square wave inverter is the simplest and most inexpensive compared to other inverter. It is generally not used commercially because of low power quality and high harmonics output, approximately 45\% [2-3]. This inverter is only used to supply simple loads such as lighting lamps or motor universal driver. Modified sine wave inverter is also called as quasi-sine wave inverter, basically is a square wave inverter modified with some dead spots between its positive and negative half-cycles so that it produces a square wave with low harmonic distortion [4]. This inverter is suitable for most types of electrical and electronic loads, type of inverter is mostly available in the market because it often more compact, lighter, and relatively low cost compared to pure sine inverter. Pure sine wave inverter produces AC voltage waveform with high quality which has a total harmonic distortion (THD) is very low even no harmonics. This type of inverter is required to supply AC load which is very sensitive such as electronic equipment, printers, copiers, audio devices, and etc. Pure sine wave inverter generates waveform output of voltage as same as utility grid standard, so it has been widely applied in renewable energy such as solar panels connected to the utility grid. This inverter has a high price in the market compared with modified sine wave because it required a complex technique to produce a pure sine wave and costly to implement [5]. 


\section{RELATED WORKS}

Various studies have been conducted on the inverter and implemented; all focused on a reduction in power losses, elimination of harmonic interference and increase the efficiency of the inverter, which aims to improve the power quality of inverter. Controlling PWM can use a variety of algorithms and can affect the quality of power [6-8].

The optimal method of PWM switching is required by pure sine inverter to generate sine wave with low harmonic. This method is often referred to as SPWM (sine pulse width modulation). There are two methods SPWM; Unipolar and Bipolar SPWM. Unipolar SPWM method is capable of producing output inverter with a lower harmonic disturbances compared with Bipolar SPWM method [9-12]. However, the SPWM output produces rectangle output wave which contains high harmonic components. For translate the SPWM output into the sinusoidal output, it's generally using LC filter that coupled in the output to the load. The Unipolar SPWM output waveform is affected by the ratio between the frequency of the reference (sine wave) and carrier (triangular wave), it is known as frequency index $\left(m_{f}\right)$. In addition, Unipolar SPWM output waveform is also influenced by the ratio between the amplitude (peak value) of the reference and carrier known as amplitude modulation $\left(m_{a}\right)$. By varying $m_{a}$, the rms output voltage can be varied [13]. Furthermore, both index value above also greatly affect the harmonic contents, improve the efficiency up to $89 \%$ [14]. In Unipolar SPWM, the magnitude of harmonics arising lower than Bipolar SPWM method [15].

\section{ORIGINALITY}

The analysis to determine the optimal amplitude modulation $\left(m_{a}\right)$ and frequency index $\left(m_{f}\right)$ for the Unipolar SPWM method using the Fourier approach is very complex. Based on this, the authors tried to perform an analysis in determining the optimal value for those two ratios in the Unipolar SPWM method using the single subject experiment research method. Through this method, data from the experimental results will be collected and processed to determine the optimal value range for those two parameters.

In this paper, determining the optimal value is carried out using Cubic Splines Interpolation (third degree polynomial interpolation). This method is expected to determine the optimal value of these parameters including the frequency modulation ratio and the amplitude modulation ratio, so that the harmonic content of output voltage and current SPWM signals can be minimized before passing through the LC filter.

The SPWM was generated by using the AtMega 16 microcontroller. The advantages of using a microcontroller are that it's very flexible in changing the SPWM signal algorithm without having to change hardware, low cost, the size is smaller and lighter than using conventional methods. Microsoft Excel software was used to process and create SPWM wave data patterns. Then the 
data pattern were uploaded and stored in a microcontroller memory (Variable Array) which has a specific data address generally known as a sine lookup table. Those data processed by the microcontroller repeatedly to form periodic waves.

\section{SYSTEM DESIGN}

The basic inverter circuits perform the task of converting 12 VDC of input to 220 VAC of output. In general as shown in Figure 2, the circuit consists of $\mathrm{DC}$ source, DC boost that used to increase DC voltage to higher level $12 \mathrm{~V}$ to $300 \mathrm{~V}$ (peak), H-bridge switching as DC to AC converter $\pm 220 \mathrm{~V}$ (rms), LC filter and load. SPWM generator, driver, and feedback as a sub-circuits integrated in the inverter regulates and ignites the four $\mathrm{H}$-bridge power switches according to the specified program [16]. The settings are as follows: when switches S1-S2 are closed and simultaneously switches S3-S4 are open, DC current flows to the load from left to right. Conversely, when switches S1S2 are open and switches S3-S4 are closed, DC current flows to the load from right to left [17]. In this paper, the selection method of $m_{a}$ and $m_{f}$ in generating Unipolar SPWM for getting minimum harmonic controlled with varied values digitally using microcontroller. Furthermore, the SPWM signal was converted to sinusoidal form by using an LC filter as well as to minimize the ripples and low harmonic contents at the inverter output.

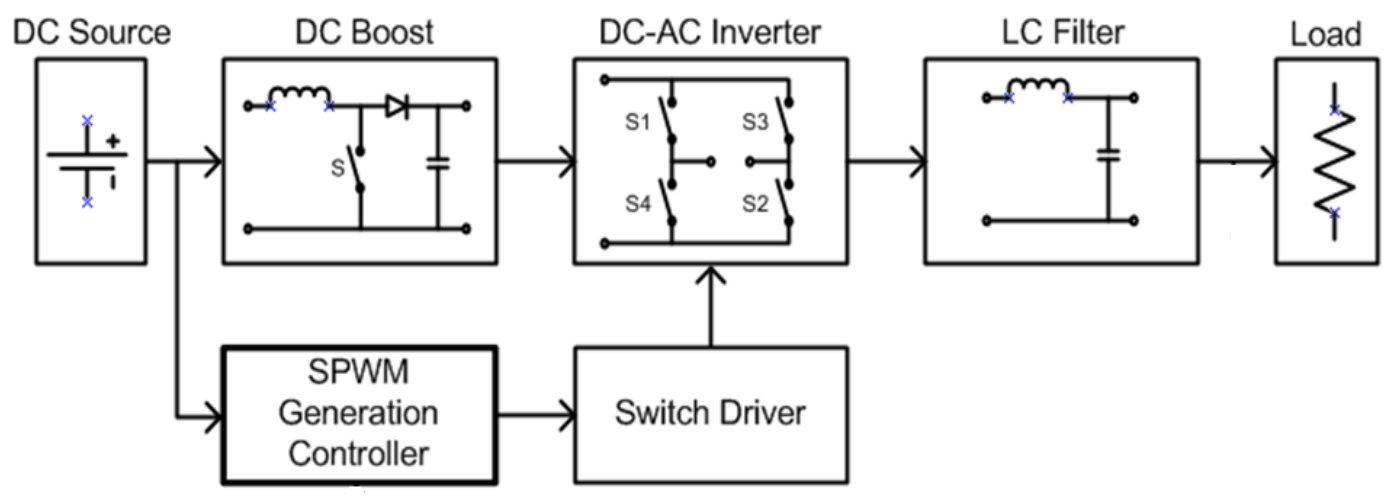

Figure 2. Design of system circuit

\subsection{Modulation Techniques}

The output of the inverter was controlled by mode Unipolar SPWM (sinusoidal pulse width modulation). Unipolar SPWM was obtained by comparing two sine waveforms as reference signals with different phase angle of $180^{\circ}\left(V_{R 1}\right.$ and $\left.V_{R 2}\right)$ and high frequency of triangular waveform as carrier signal $\left(V_{C r}\right)$ [18]. The principle of SPWM can be seen as illustrated in Figure 3 and the resulting wave can be seen in Figure 4. Widths of the pulses $\left(V_{o}\right)$ are proportional to average value of the sinusoidal. Output pulses of this operation can be directly delivered to the switching devices of the full bridge VSI. 


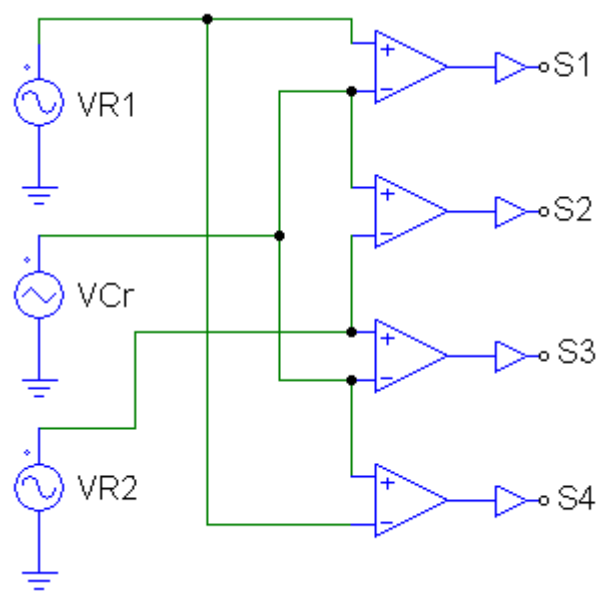

Figure 3. Principle of SPWM Signal Generation
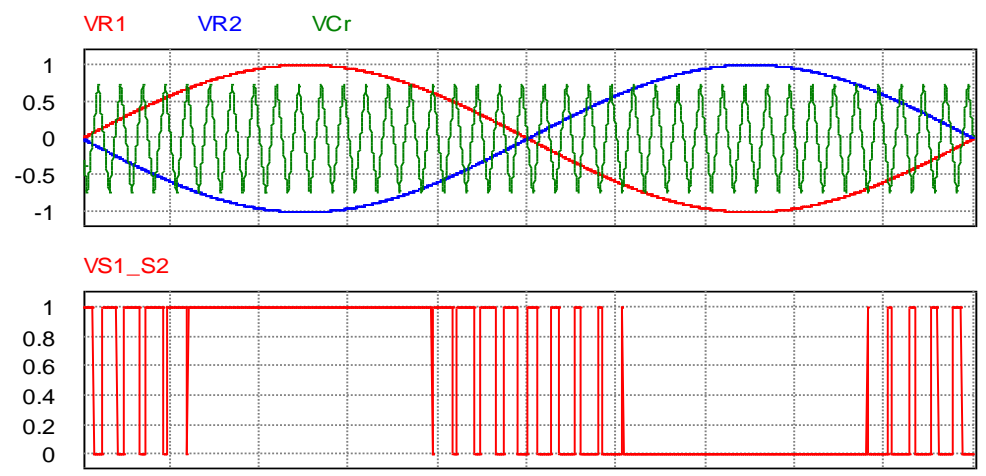

VS3_S4

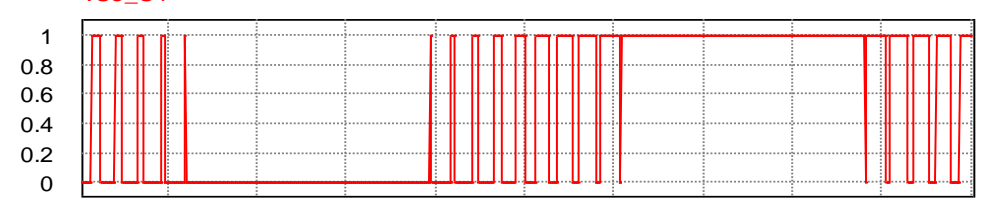

Vo

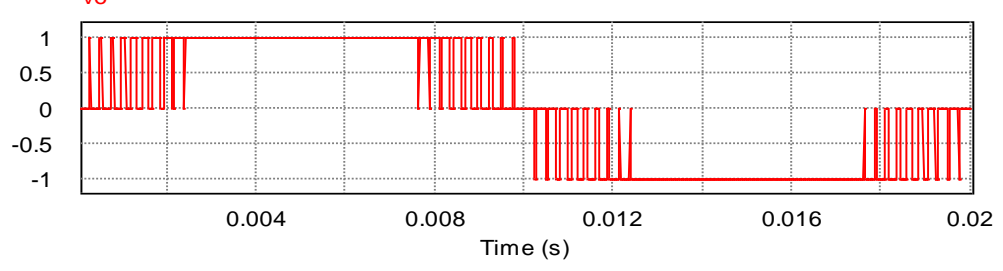

Figure 4. Output signal of SPWM generation process

Comparison between the amplitude of reference signal and the amplitude of the carrier signal is defined as the ratio of amplitude modulation $\left(m_{a}\right)$. If the reference signal $V_{R}$, performs at a frequency $f_{R}$, amplitude $A_{R}$, and the carrier signal $V_{C r}$ performs at a frequency $f_{C r}$, amplitude $A_{C r}$, then the ratio 
of amplitude modulation $\left(m_{a}\right)$, which is also called the modulation index can be determined as follows [19]:

$$
m_{a}=\frac{A_{R}}{A_{c r}}
$$

From equation 1, the amplitude of the fundamental component of the output voltage $\mathrm{AC}\left(A_{0}\right)$ can be determined as follows:

for Half bridge VSI ;

$$
A_{0}=\frac{V_{i}}{2} \cdot m_{a}
$$

for Full bridge VSI ;

$$
A_{0}=V_{i} \cdot m_{a}
$$

where, $A_{0}$ is amplitudo of fundamental output AC voltage, $V_{i}$ is input DC voltage. Comparison between the triangle frequency and the control frequency is defined as the frequency ratio. Frequency ratio $\left(m_{f}\right)$ is often referred to as the carrier frequency can be determined as follows:

$$
m_{f}=\frac{f_{C r}}{f_{R}},
$$

The values of $m_{a}$ and $m_{f}$ will affect the other parameters, for examples, if $m_{a} \leq 1$, which is a linear region where $A_{0}$ will be directly proportional to $m_{a}$. The amplitude of the harmonics of the AC output voltage is a function of $m_{a}$ and does not depend on $m_{f}$, for $m_{f}>9$. For, $m_{f}<21$, the carrier voltage $V_{C r}$ and reference voltage $V_{R}$ should be harmonized in order to $m_{f}$ is an integer. If not, it will appear sub harmonics on the AC output voltage $V_{o}$. For large values of $m_{f},\left(m_{f}>21\right)$, the sub harmonics are negligible if using an asynchronous PWM technique [20].

Due to $m_{a}$ and $m_{f}$, power switching convert the linear DC input voltage convert into the chopped rectangle waveform with different duty cycle as shown in Fig. 4, and it alternates the sign of the output every half period. The number of pulses for the half period is $M$, where $\alpha_{1}, \alpha_{2}, \ldots, \alpha_{M}$ are the commutation angle. This wave is a periodic function that can be decomposed into Fourier function. The number of pulses $\mathrm{M}$ can be odd or even, since the waveform is an odd symmetry and half-period symmetry the inverter output voltage can be expressed by the following equation: 


$$
\begin{aligned}
& V_{0}(t)=\sum_{n=1}^{\infty} B_{n} \sin (n \omega t), \\
& B_{n}=\frac{4}{n \pi} \sum_{i=1}^{M}(-1)^{i+1} \cos \left(n \alpha_{i}\right),
\end{aligned}
$$

where, $B_{n}$ is Fourier Coefficient, $i=1 ; 2 ; 3 ; . . ; M, n=1 ; 3 ; 5 ; \ldots, \omega=2 \pi / T$ is fundamental frequencies that multiples of this frequency $(n \omega)$ that called harmonic frequencies, and the commutation angle satisfying the following conditions; $0<\alpha_{1}<\alpha_{2}<\ldots<\alpha_{M}<\pi / 2$.

\subsection{Cubic Spline Approach}

Cubic Spline is interpolation that used to determine the mean value between the data points that are relatively free of errors. This method is to adjust the curve, directly through the data points and use the curve to predict the value of the center. Cubic Spline interpolation applying third-order polynomial form for a subset of the data points. This function is used to connect each pair of data points that shaped curve. So that the relationship between the cube adjacent equation visually looks smoother than any others interpolation [21]. Determination of the third-order polynomial equation for each interval between points (knots), as shown in the equation below [22]:

$$
f_{i}(x)=a_{i} x^{3}+b_{i} x^{2}+c_{i} x+d_{i}
$$

Thus, for $n+1$ data points $(\mathrm{i}=0,1,2, \ldots, n)$, there are $n$ interval data and $4 n$ unknown constants that must be met to evaluate Cubic Splines. For example of the value of $n=3$, then the number of data points that form is $n+1=4$ pairs of data, the number of intervals that form of $n=3$, ie; $i=1(x 0 \leq x \leq x 1)$, $\mathrm{i}=2(\mathrm{x} 1 \leq \mathrm{x} \leq \mathrm{x} 2)$, and $\mathrm{i}=3(\mathrm{x} 2 \leq \mathrm{x} \leq \mathrm{x} 3)$.

The number of unknown constants that must be met for $4 \mathrm{~N}=12$, which is composed of $(2 n-2)+(2)+(n-1)+(n-1)+(2)=12$. An illustration of Cubic Splines formed by 4 pairs of data ( 3 interval data) is shown in Figure 5 below.

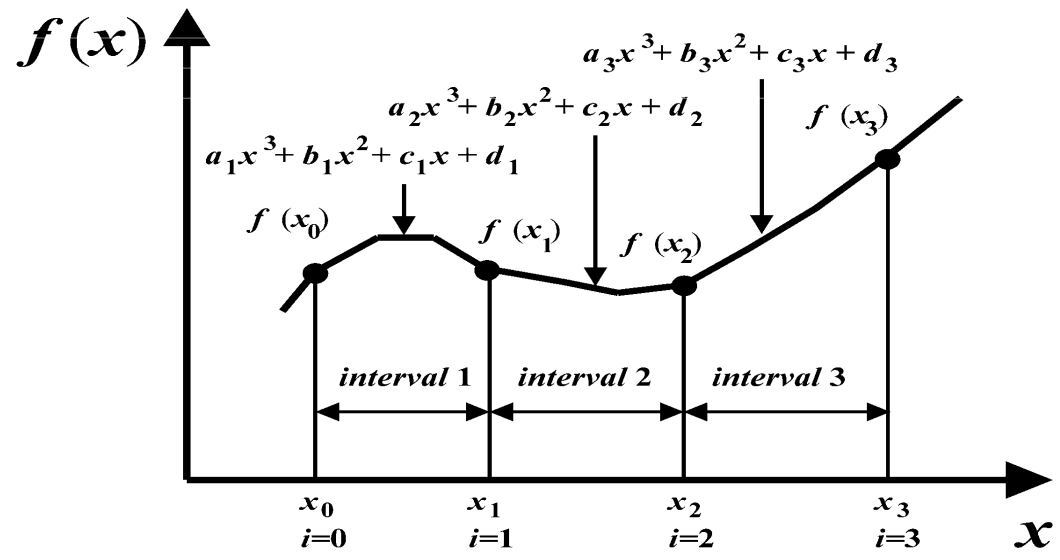

Figure 5. Cubic Splines Illustration [22] 
The equation of Cubic Spline interpolation for $i$-th data interval is as follows [23]:

$$
\begin{aligned}
f_{i}(x)= & \frac{f_{i}^{\prime \prime}\left(x_{i-1}\right)}{6\left(x_{i}-x_{i-1}\right)}\left(x_{i}-x\right)^{3}+\frac{f_{i}^{\prime \prime}\left(x_{i}\right)}{6\left(x_{i}-x_{i-1}\right)}\left(x-x_{i-1}\right)^{3} \\
& +\left[\frac{f\left(x_{i-1}\right)}{\left(x_{i}-x_{i-1}\right)}-\frac{f^{\prime \prime}\left(x_{i-1}\right)\left(x_{i}-x_{i-1}\right)}{6}\right]\left(x_{i}-x\right) \\
& +\left[\frac{f\left(x_{i}\right)}{\left(x_{i}-x_{i-1}\right)}-\frac{f^{\prime \prime}\left(x_{i}\right)\left(x_{i}-x_{i-1}\right)}{6}\right]\left(x-x_{i-1}\right),
\end{aligned}
$$

For every interior knots, the equation is as follow:

$$
\begin{aligned}
& \left(x_{i}-x_{i-1}\right) f^{\prime \prime}\left(x_{i-1}\right)+2\left(x_{i+1}-x_{i-1}\right) f^{\prime \prime}\left(x_{i}\right)+\left(x_{i+1}-x_{i}\right) f^{\prime \prime}\left(x_{i+1}\right) \\
& =\frac{6}{\left(x_{i+1}-x_{i}\right)}\left[f\left(x_{i+1}\right)-f\left(x_{i}\right)\right]+\frac{6}{\left(x_{i}-x_{i-1}\right)}\left[f\left(x_{i-1}\right)-f\left(x_{i}\right)\right],
\end{aligned}
$$

In this paper the Cubic Splines was used to determine the minimum point from the number of harmonics (THDR) measurement results and calculation results, under the condition; harmonic $(\eta)$ refers to $f_{i}(x), m_{a}$ and $m_{f}$ refer to $(x)$, the number of data sampling refers to $i$, and the interval of data refers to $n$.

\section{EXPERIMENTAL RESULTS AND ANALYSIS}

In this proposed paper, harmonic content of inverter was measured at the output voltage $\left(V_{o}\right)$ as basic circuit of single phase Full bridge VSI without filter as shown in Figure 2 and with LC filter connected in parallel with load. The parameter of system design and sizing are listed in Table 1.

Table 1. Simulation parameters for the proposed system

\begin{tabular}{|l|l|}
\hline \multicolumn{1}{|c|}{ Parameters } & \multicolumn{1}{c|}{ Values } \\
\hline Reference signal frequency & $50 \mathrm{~Hz}$ \\
\hline Reference signal amplitude & $1 \mathrm{volt}$ \\
\hline Carrier signal frequency & $2-10 \mathrm{kHz}$ \\
\hline Carrier signal amplitude & $0.4-1.2$ volt \\
\hline Mosfet & Refer to datasheet IRF 8010 \\
\hline Input voltage & $12 \mathrm{Vdc}$ \\
\hline Load & $2 \mathrm{k} \Omega$ \\
\hline L (LC filter) & $0.32-5.07 \mathrm{mH}$ \\
\hline C (LC filter) & $5-10 \mu \mathrm{F}$ \\
\hline
\end{tabular}


Recommended measurement and DC-AC inverter configuration is shown as Figure 6 below:

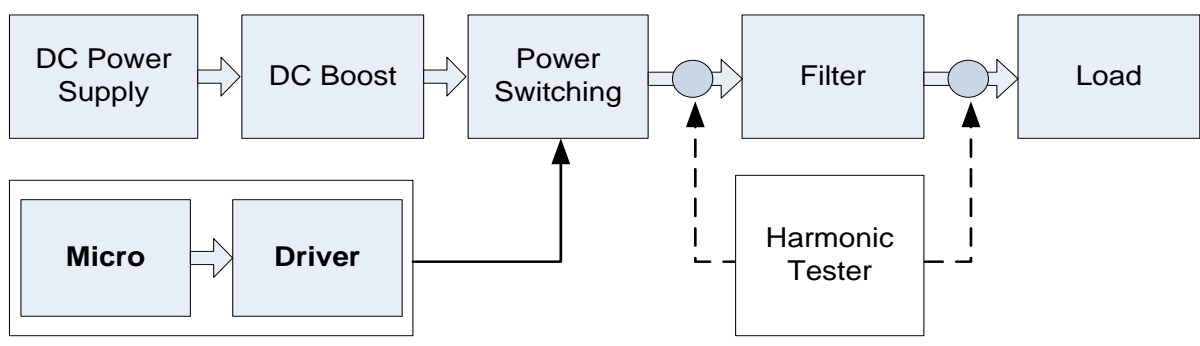

Figure 6. Experiment Block Diagram

DC Power Supply provides the DC voltage used 12Vin this experiment. This voltage used as the operation of the microcontroller input (Vcc), driver, and power switching that convert to ac. The minimum system of AtMega 16microcontroller used for generate Unipolar SPWM signal. Programming techniques from PROGISP software are used to vary the values of amplitude modulation and frequency ratio. In the first stage the frequency ratio was kept constant while the amplitude modulation was controlled with values such as: $0.2,0.4,0.6,0.8,1.0,1.2$, and 1.4 . Conversely in the second stage the amplitude modulation was kept constant while the frequency ratio was controlled with values varying from $20,24,30,36,40$ 60, 72, 90, 100, 110, 120,180 . Overall, the experimental setup can be seen in Figure 7 below:

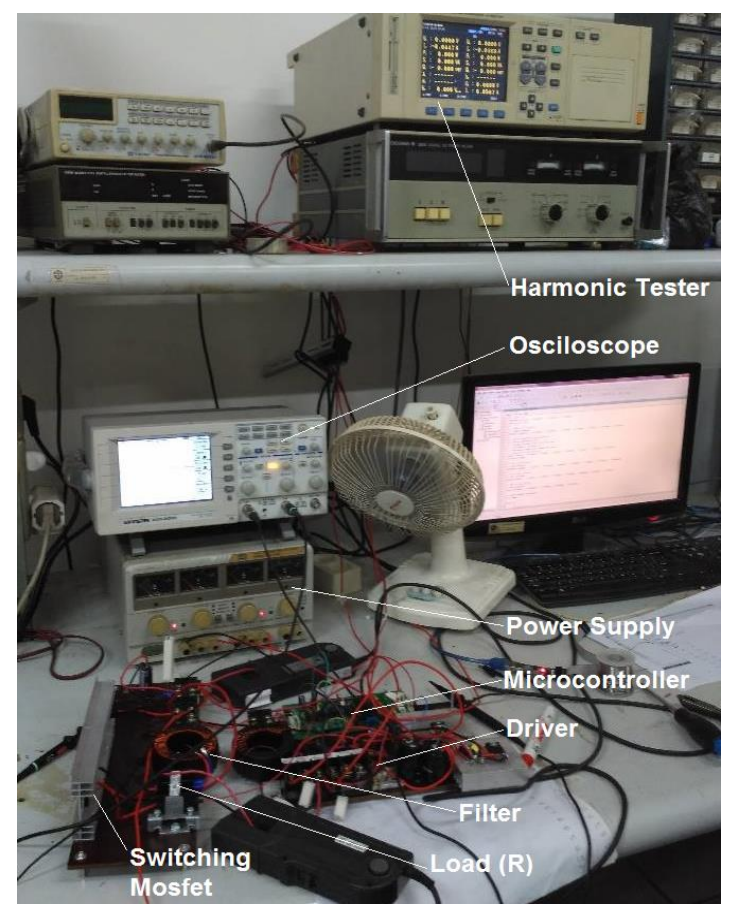

Figure 7. Overall of experiment setup 
The frequency of the carrier signal (triangle wave) was set in the range 2 - $10 \mathrm{kHz}$, while the frequency of the reference signal (sinusoidal wave) follows the standard utility frequency of $50 \mathrm{~Hz}$. Driver is a control circuit that serves to amplify the signal from the output of microcontroller pin to be able to ignite the power switching circuit (mosfet). Drivers using the IR2130 component that has three pairs of pins for ignition low voltage side and high voltage side, where each pin can be used to ignite two MOSFETs. Power Switching circuit (MOSFETs) arranged in a full bridge configuration using IRF 8010. A $2 \mathrm{k} \Omega$ as a load mounted on the output of full bridge (mosfet) for measuring of inverter output.

The experiment was conducted simultaneously with the data retrieval process. The data collected in the experimental process was still in the form of rough data, so it should be compiled and grouped according to research requirements.

\subsection{Testing Without Filter}

The results of grouping data from testing without using filter by providing a variation of $m_{f}$ and a fixed $m_{a}$ value of seven tests. From the seven tests, the best results obtained from the three values of $m_{a}: 0.8,1.0$, and 1.2 as shown in Figure 8.

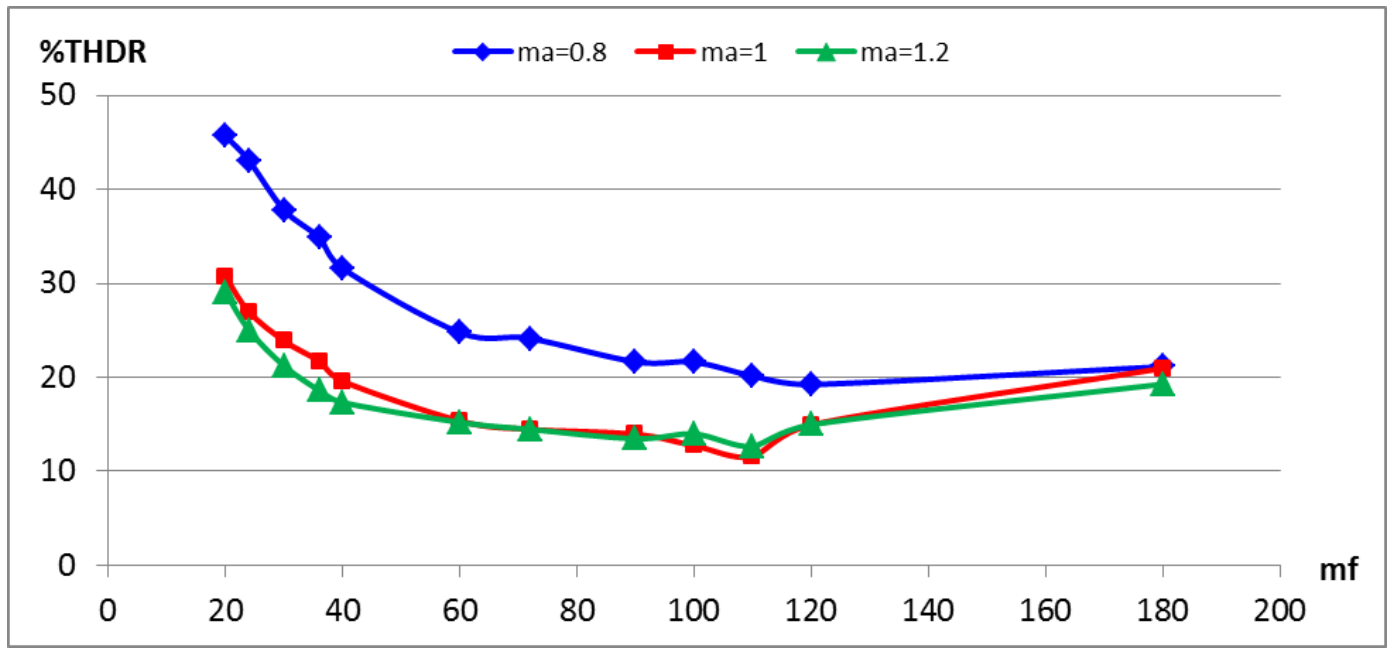

Figure 8. THDR precentage curve of the inverter output voltage on $m_{f}$ variation, $m_{a}=0.8,1.0$, and 1.2 .

From Figure 8 it can be seen that the minimum harmonic value of the SPWM output voltage obtained when the $m_{f}$ value is 110 based on the selected curve i.e. $m_{a}=1$. 


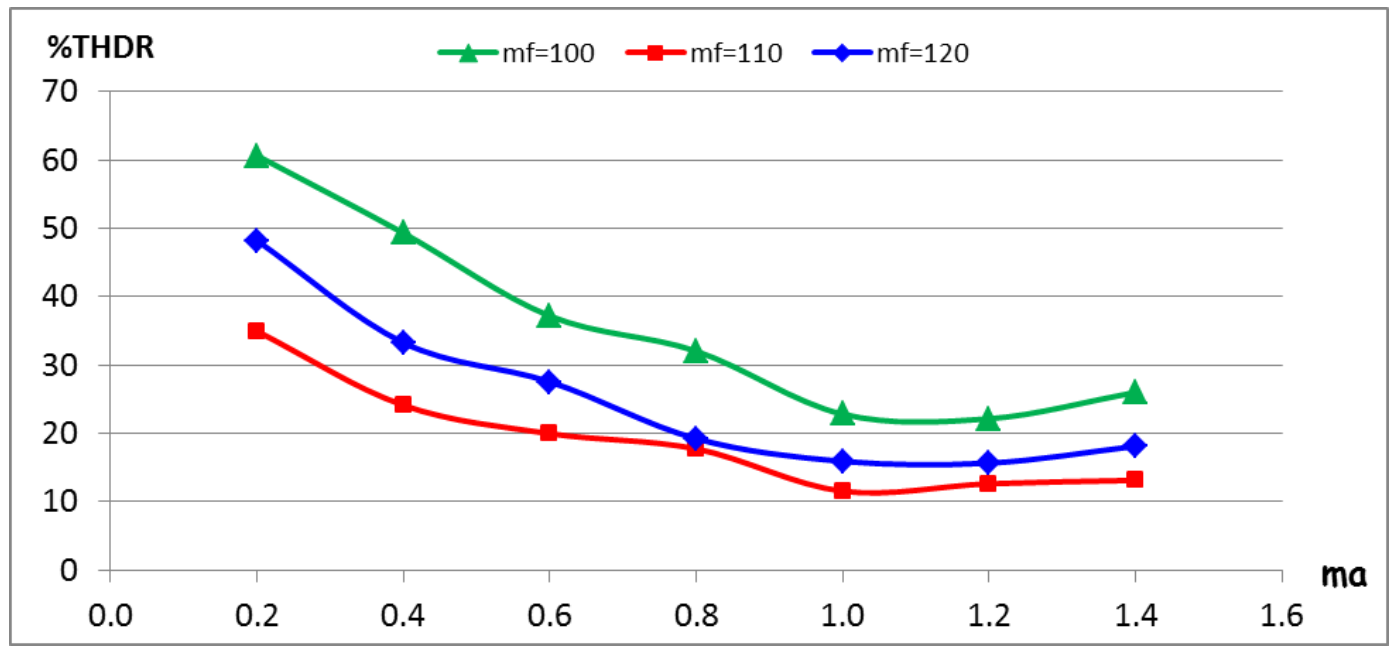

Figure 9. THDR precentage curve of the inverter output voltage on various $m_{a}, m_{f}=$ 100,110 , and 120.

Furthermore, the results of grouping data from the test without using filter by providing a variation of $m_{a}$ and a fixed $m_{f}$ value of twelve tests. From the twelve tests, the best results are obtained from the three selected values of $m_{f} ; 100,110$, and 120 as shown in Figure 9. It can be seen that the minimum harmonic value of the inverter output voltage obtained when the $m_{a}$ value is 1.0. Thus based on the two curves above (Figure 8 and Figure 9) it is found that the minimum value of harmonic for the inverter output voltage is achieved at the $m_{a}$ value of 1.0 and $m_{f}$ is 110 , with the \%THDR value for the inverter output voltage of $11.54 \%$. The SPWM output waveforms of voltage and current without the LC filter are shown as in Figure 10 that displayed using a Harmonic Tester.

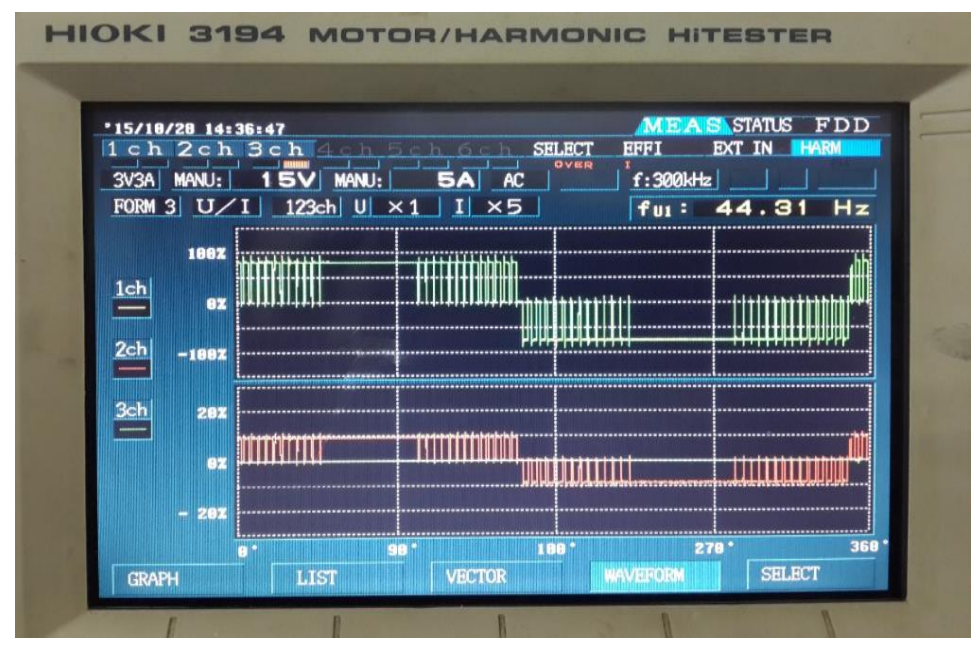

Figure 10. Inverter output waveform measurement without LC filter, voltage (green) and current (red) 
Here the Cubic Splines interpolation was used to estimate the $m_{f}$ value of the above test results in order to obtain minimum \%THDR for the inverter output voltage. Based on the curve in Figure 8, four data points are taken that have the same interval. The value of $m_{f}$ which has the same interval is data with value of $90,100,110$ and 120 . If it is assumed the minimum value of \%THDR for the inverter output voltage at $m_{f}=109$, then the data is in the range: 100 - 110 with range of \%THDR : $12.72 \%-11.54 \%$. These data are then processed based on the interpolation cubic splines equation (equations 8 and 9), so that from this calculation, for the value $m_{f}=109$, the \%THDR for the inverter output voltage is 11,47839. Calculation of the Cubic Splines interpolation was repeated for some $m_{f}$ values in the range $100-110$, then the estimated value of \%THDR for the inverter output voltage can be obtained as shown in Table 2.

Table 2. Estimated value of \%THDR inverter output voltage to the change in $m_{f}$

\begin{tabular}{|c|c|}
\multicolumn{3}{|c|}{ value } \\
\hline $\boldsymbol{m} \boldsymbol{f}$ & \%THDR \\
\hline 101 & 12.53159 \\
102 & 12.33456 \\
103 & 12.13801 \\
104 & 11.95104 \\
105 & 11.78275 \\
106 & 11.64224 \\
107 & 11.53861 \\
108 & 11.48096 \\
$\mathbf{1 0 9}$ & $\mathbf{1 1 . 4 7 8 3 9}$ \\
\hline
\end{tabular}

Based on Table 2 it appears that a minimum of \%THDR for the inverter output voltage is reached when $m_{f}$ is 109 , with \%THDR of $11.47839 \%$ and $m_{a}$ value being 1.0.

\subsection{Testing With Filter}

The testing was carried out by involving LC filter connected in parallel with the inverter output voltage. Testing with LC filters was done by giving three conditions from the cut-off frequency $\left(f_{o}\right)$, ie:

- Filter with $f_{o}=1000 \mathrm{~Hz} ; \mathrm{C}=5 \mu \mathrm{F}$; and $\mathrm{L}=5.07 \mathrm{mH}$,

- Filter with $f_{o}=4000 \mathrm{~Hz} ; \mathrm{C}=5 \mu \mathrm{F}$; and $\mathrm{L}=0.32 \mathrm{mH}$,

- Filter with $f_{o}=9000 \mathrm{~Hz} ; \mathrm{C}=10 \mu \mathrm{F}$; and $\mathrm{L}=0.32 \mathrm{mH}$.

The result of grouping data from the test without using a filter by giving varies of $m_{f}$ and a fixed value of $m_{a}$, can be seen as in Figure 11. 


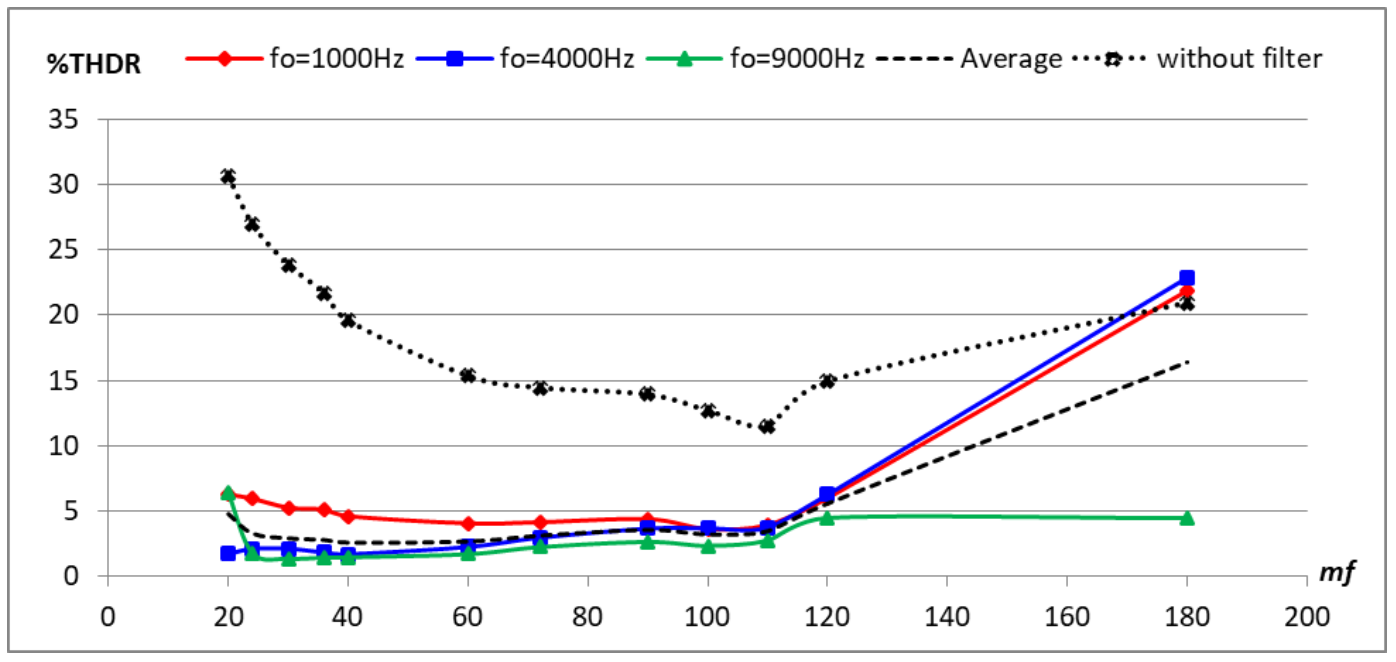

Figure 11. \% THDR curve of the inverter output voltage with LC filter on $m_{f}$ variation, $m_{a}=1.0$.

From Figure 11 it can be seen that the minimum harmonic average of the three conditions (cut-off frequency) was obtained when the $m_{f}$ value is 40 . Furthermore, the results of grouping data from the test by giving a variable $m_{a}$ and $m_{f}=40$ as shown in Figure 12.

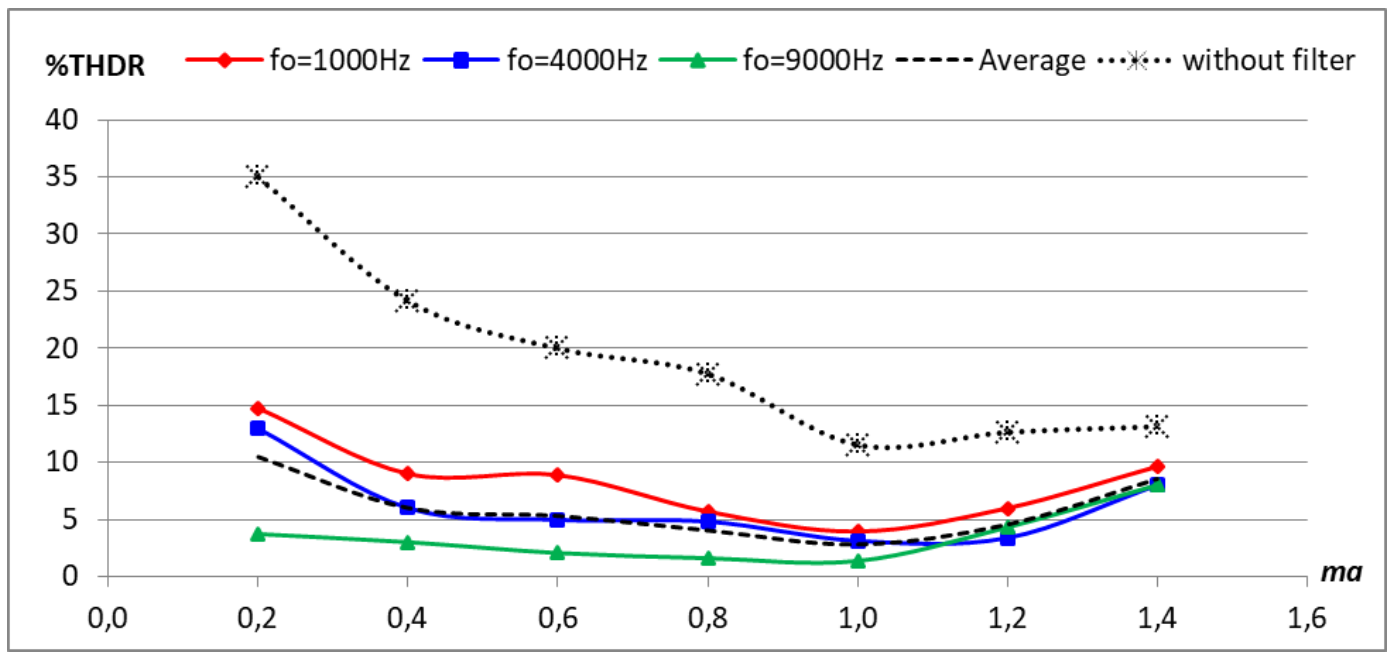

Figure 12. \% THDR curve of the inverter output with LC filter on $m_{a}$ variation, $m_{f}=40$.

From the curves in Figure 11 and 12 shows that the minimum \%THDR for inverter output voltage is achieved at the value $m_{a}=1.0$ and $m_{f}=40$, with the \%THDR value is $2.61 \%$, the difference is about $8-10$ percent lower than without filter to the smallest $m_{a}$ value. The sinusoidal output waveforms of voltage and current after using the LC filter are shown as in Figure 13. 


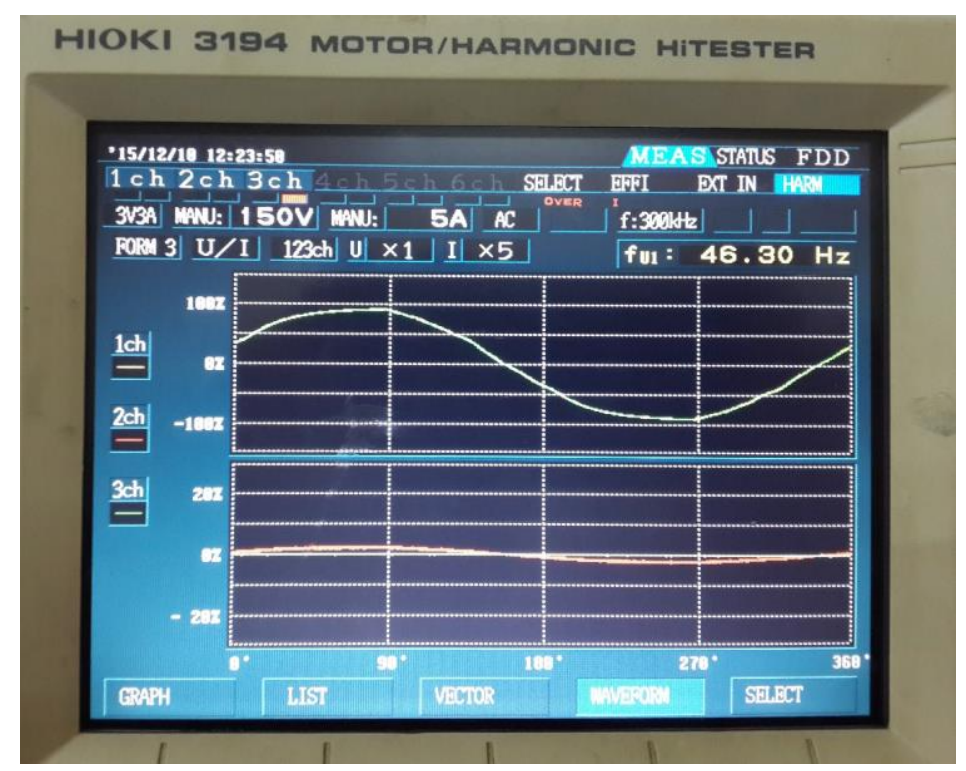

Figure 13. Inverter output waveform measurement using LC filter, voltage (green) and current (red)

The minimum values of harmonics at the inverter output voltage is found at intervals of $40-50$ with \%THDR value of $2.61 \%-2.46 \%$. Calculation of the Cubic Splines Interpolation (equations 8 and 9) was repeated for some $m_{f}$ values in the range $40-50$, and then the estimated value of \%THDR for the inverter output voltage can be obtained as shown in Table 3.

Table 3. Estimated value of \%THDR inverter output voltage with LC filter to the change in $m_{f}$ value

\begin{tabular}{|c|c|}
\hline $\boldsymbol{m} \boldsymbol{f}$ & \%THDR \\
\hline 41 & 2.569610 \\
42 & 2.533280 \\
43 & 2.503954 \\
44 & 2.481243 \\
45 & 2.464758 \\
46 & 2.454110 \\
47 & 2.448910 \\
$\mathbf{4 8}$ & $\mathbf{2 . 4 4 8 7 6 8}$ \\
49 & 2.453296 \\
50 & 2.462105 \\
\hline
\end{tabular}

Based on Table 3 it appears that a minimum of \%THDR for the inverter output voltage is reached when $m_{f}$ is 48 , with \%THDR of $2.448768 \%$ and $m_{a}$ value being 1.0.

Here it can be noted that the proposed method can be useful in the initial design of the inverter based on the capacity and load types in relation to the 
harmonic content. Determination of the smallest harmonics from SPWM resulted from sampling of hundreds of variations in $m_{a}$ and $m_{f}$ values which successfully carried out using Cubic Splines interpolation. Furthermore, the effect of variations in load types can be carried out by selecting the proper type of filter in minimizing ripple and low harmonic distortion from the inverter output sine waveform.

\section{CONCLUSION}

The experimental results show that the amplitude modulation index $\left(m_{a}\right)$ and the frequency ratio $\left(m_{f}\right)$ formed from the reference signal and carrier signal affects the harmonic content of the generated inverter SPWM. Experiments have shown that of the many combinations of $m_{a}$ and $m_{f}$ values, the use of the Cubic Spline interpolation method has proven successful in determining the correct $m_{a}$ and $m_{f}$ values for the minimum harmonics of the SPWM output of $11.48 \%$ before passing through the filter. Moreover, the addition of filter is not only useful for generating ac sinusoidal wave at the inverter output voltage but can also minimize low harmonic distortions. In this experiment, the optimal THD value produced was $2.45 \%$ and this value meets the allowable standard of utility harmonic which is less than $3 \%$.

\section{Acknowledgements}

The author would like to thank all colleagues, researchers, technicians at the Research Center for Electric Power and Mechatronics, Indonesian Institute of Sciences for all the support and assistance that has been given.

\section{REFERENCES}

[1] M. H. Rashid, Electric Renewable Energy Systems, Elsevier, ISBN: 9780-12-804448-3, pp. 355, 2016.

[2] L. F. Aguiar, E. Grzeidak, J. P. C. L. da Costa, Trade off Between Total Harmonic Distortion and Efficiency in Coupling of a Classical Bridge Inverter and a Photovoltaic System, Proceedings of Ises Solar World Congress, Kassel, Germany, pp. 2820, 2011.

[3] S. V. Rode, S. A. Ladhake, A Modified Method for Harmonic Elimination, International Journal of Computer and Electrical Engineering, Vol. 3, No. 4, pp. 493-496, 2011.

[4] S. Sheng, P. Li, B. Lehman, Parallel Operation of Digital Controlled Modified Sine Wave Inverters, Energy Conversion Congress and Exposition (ECCE), IEEE Conference Publications, pp. 1628-1634, 2013,

[5] M. B. Cheema, S. A. Hasnain, M. M. Ahsan, M. Umer, G. Ahmad, Comparative Analysis of SPWM and Square Wave Inverters, Environment and Electrical Engineering (EEEIC), 2015 IEEE 15th International Conference, pp. 38 - 42, 2015.

[6] N. Tutkun, Improved power quality in a single-phase PWM inverter voltage with bipolarnotches through the hybrid genetic 
algorithms, Expert Systems with Applications, Vol. 37, pp. 5614-5620, 2010.

[7] K. K. Tan, S. B. Masri, Grid Tie Photovoltaic Inverter for Residential Application, Modern Applied Science, Vol. 2, No. 4, pp. 200-211, 2011.

[8] M. C. Di Piazza, M. Pucci, Techniques for efficiency improvement in PWM motor drives, Electric Power Systems Research, Vol. 136, pp. 270280, 2016.

[9] T. F. Wu, C. L. Kuo, K. H. Sun, H. C. Hsieh, Combined Unipolar and Bipolar PWM for Current Distortion Improvement During Power Compensation, IEEE Transactions On Power Electronics, Vol. 29, No. 4, pp. 1702-1709, 2014.

[10] P. Vijayarajan, A. Shunmugalatha, H. H. Sait, Development of modified carrier based PWM scheme for single phase $\mathrm{H}$-bridge Inverter fed isolated wind-PV systems, Solar Energy, Vol. 126, pp. 208-219, 2016.

[11] N. Ismail, A. Permadi, A. Risdiyanto, B. Susanto, M. A. Ramdhani, The Effect of Amplitude Modulation Index and Frequency Modulation Index on Total Harmonic Distortion in 1-Phase Inverter, IOP Conference Series: Materials Science and Engineering, Vol. 288, No. 012107, pp. 1-6, 2017.

[12] E. H. E. Aboadla, S. Khan, M. H. Habaebi, T. Gunawan, B. A. Hamidah, M. B. Yaacob, Effect of Modulation Index of Pulse Width Modulation Inverter on Total Harmonic Distortion for Sinusoidal, 2016 International Conference on Intelligent Systems Engineering (ICISE), IEEE Conference Publications, Islamabad, Pakistan, pp. 1-5, 2016

[13] S. K. Peddapelli, Recent Advances in Pulse Width Modulation Techniques and Multilevel Inverters, World Academy of Science, Engineering and Technology, International Journal of Electrical, Computer, Energetic, Electronic and Communication Engineering, Vol. 8, No. 3, pp. 593-601, 2014.

[14] P. H. Zope, P. G. Bhangale, P. Sonare, S. R. Suralkar, Design and Implementation of carrier based Sinusoidal PWM Inverter, International Journal of Advanced Research in Electrical, Electronics and Instrumentation Engineering, Vol. 1, Issue. 4, pp. 230-236, 2012.

[15] A. Namboodiri, H. S. Wani, Unipolar and Bipolar PWM Inverter, International Journal for Innovative Research in Science \& Technology, Vol. 1, Issue. 7, pp. 237-243, 2014.

[16] K. Dhivya, R. Anandaraj, Pulse Width Modulator for Voltage Regulation in Voltage Source Inverter, International Journal of Engineering Trends and Applications, Vol. 2, Issue. 2, pp. 16-21, 2015.

[17] A. Risdiyanto, B. Susanto, N. A. Rachman, A. Muqorobin, T. D. Atmaja, H. P. Santosa, Design of Constant Output Voltage DC-AC Inverter for Batteryless Solar PV System, Bulletin of Electrical Engineering and Informatics, Vol. 9, No. 4, pp. 1326-1334, 2020.

[18] S. H. Pawar, A. S. Kulkarni, C. A. Jambhulkar, Effect of Carrier Frequency on the Performance of Three Phase SPWM Inverter, 
International Journal of Science, Engineering and Technology Research (IJSETR), Vol. 4, Issue. 9, pp. 3019-3023, 2015.

[19] B. G. Shivaleelavathi, Chinmayi, V. Yatnalli, Review on Multi Level Inverter Topologies and Control Strategies for Solar Power Conversion, EMITTER International Journal of Engineering Technology, Vol. 8, No. 2, pp. 295-315, 2020.

[20] M. H. Rashid, Power Electronics Handbook, Elsevier, Third Edition, pp. 359-361, 2011.

[21] Y. Chu, S. Li, M. Wang, Y. Che, Research of Image Magnifying Algorithm Based on Cubic Spline Interpolation, International Conference on Electronic, Mechanical Engineering, and Information Technology, IEEE Conference Publications, pp. 3391-3394, 2011.

[22] M. D. Araujo, A. Medina, R. C. Magana, A. Ramirez, Periodic Steady State Assessment of Microgrids with Photovoltaic Generation Using Limit Cycle Extrapolation and Cubic Splines, Energies 2018, 11, 2096, pp. 1-16, 2018.

[23] S. C. Chapra, R. P. Canale, Numerical Methods for Engineers, McGrawHill, Sixth Edtion, pp. 515, 2010. 